\title{
Lipoma of the Right Atrium
}

\author{
Wilson Luiz da Silveira, Max Weyler N ery, Erica Coelho Garcia Soares, Adélio Ferreira Leite, \\ Hernando N azzetta, Márcia Andery Ludovico Batista, Cacilda Pedrosa de O liveira, \\ Vilmondes Gonçalves de O liveira
}

\author{
Goiânia, GO - Brazil
}

The patient is a 54-year-old asymptomatic male with a tumor in the right atrium that was diagnosed on transesophageal echocardiography and confirmed as a lipoma of the right atrium on computerized tomography. The patient underwent surgical repair with extracorporeal circulation. The tumor was resected, and its base of implantation in the atrium was repaired with a flap of bovine pericardium. The diagnosis of lipoma was confirmed on histopathological examination. Locating of the tumor with the aid of transesophageal echocardiography was very useful in the strategy of cannulation of the venae cava for installation of the circuit of extracorporeal circulation. The patient had a good postoperative evolution.

Primary cardiac tumors are rare. Their incidence ranges from $0.001 \%$ to $0.28 \%$ according to the report of an autopsy series ${ }^{1}$. In $75 \%$ of cases, they are benign, and the most frequent are myxomas, lipomas, and rhabdomyomas. The remaining $25 \%$ are malignant, and the most common are rhabdomyosarcomas and angiosarcomas ${ }^{2}$. Lipomas account for $8.4 \%$ of primary cardiac tumors. Secondary or metastatic tumors are 30 to 40 times more frequent ${ }^{2}$.

Cardiac tumors may involve the endocardium, the myocardium, the pericardium, and the emergence of the great vessels ${ }^{3}$.

The signs and symptoms of cardiac lipomas depend on the location of the tumor and result from valvar dysfunction or cardiac compression, which hinder cardiac filling and emptying ${ }^{4}$. Lipomas located close to the cardiac valves may have early symptoms because of obstruction or audible murmurs ${ }^{5}$. Lipomas of the right atrium, of the interatrial septum, and of the right ventricle may predispose to the development of arrhythmias ${ }^{6}$. Lipomas that superficially involve

Hospital Santa Genoveva - Grupo CentroCárdio - Goiânia Mailing address: Wilson Luiz da Silveira - Rua 9, 504/1301 - Setor Oeste 74110-100 - Goiânia, GO - E-mail: ccardio@internetional.com.br English version by Stela Maris C. e Gandour the epicardium or mainly the myocardium may remain asymptomatic during a prolonged time and may reach very large dimensions ${ }^{7}$. Lipomas may occur at any age and with an equal frequency in both sexes ${ }^{8}$.

The first successful resection of an epicardial lipoma was performed in 1954 by Maurer et al. ${ }^{9}$ and that of an intracavitary lipoma was performed in 1964.

We report a rare case of an intracardiac mass diagnosed with the aid of transesophageal echocardiography and computerized tomography and whose surgical treatment and anatomicopathological study confirmed the diagnosis of lipoma.

\section{Case report}

We report the case of a 54-year-old male patient with a history of fever of undetermined origin. On physical examination, the patient was in regular general condition, eupneic, afebrile, acyanotic, anicteric, with healthy coloring, hydrated, with no jugular turgescence, and no edemas. His ictus cordis could be seen on the $5^{\text {th }}$ left intercostal space, on the left midclavicular line, and comprised 2 fingertips. His cardiac rhythm was regular and 2-beat, with cardiac sounds of normal intensity, no murmurs, but 1 protodiastolic noise could be heard, which was later defined as a tumoral "plop" (tumor shock).

The biochemical study, electrocardiography, and chest teleradiography showed no alterations. Transthoracic echocardiography was performed with great technical difficulty and revealed a mass inside the right atrium. This led us to perform transesophageal echocardiography, which showed a dilated right atrium, the presence of a large homogeneous round mass measuring $6.0 \times 5.0 \mathrm{~cm}$ inside the atrium. This mass was adhered to the lateral wall of the right atrium and had little mobility towards the tricuspid valve (fig. 1). A chest computerized tomography was also performed, with axial sections of $5 \mathrm{~mm}$ and $10 \mathrm{~mm}$ in thickness, after intravenous infusion of the contrast medium and study of 1-mm sections with a high-resolution technique. This showed a lowdensity failure in right atrial filling measuring $7.0 \mathrm{~cm}$ in the 


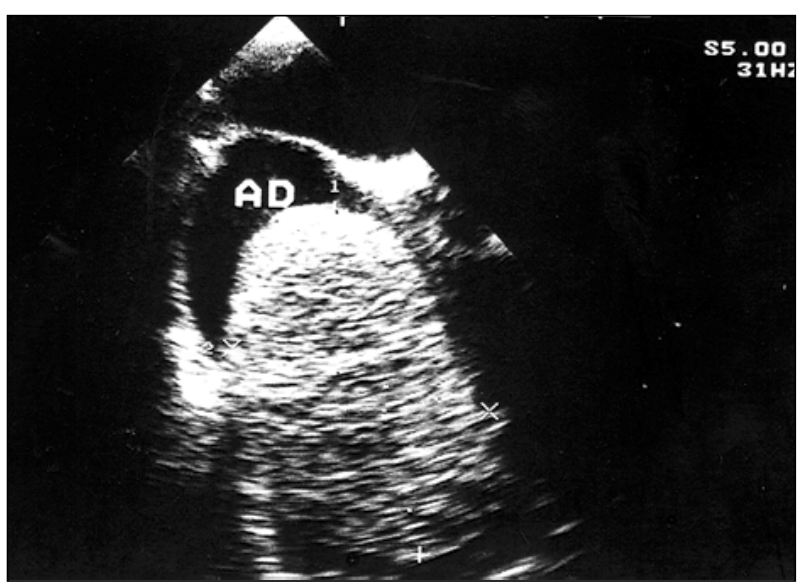

Fig. 1 - Transesophageal echocardiography showing a homogeneous mass of large dimensions occupying almost the entire right atrial cavity.

anteroposterior axis and $5.0 \mathrm{~cm}$ in the transversal axis (fig. 2). Chest computerized tomography suggested the diagnosis of right atrial lipoma.

We chose surgical treatment for resecting the tumor. The patient underwent cardiac surgery through median thoracotomy, with heparinization and extracorporeal circulation, under normothermia. Cannulation was performed with pouches in the venae cava and not in the atrial auricle, as is usually performed, and guided by echocardiographic orientation of the tumor site. Later, the right atrium was opened, and a yellowish encapsulated homogeneous mass with an elastic consistency and greasy appearance was identified. The postoperative period was uneventful.

The gross examination revealed a yellowish specimen with a nodular appearance and elastic consistency, which measured $6.7 \times 6.5 \times 5.0 \mathrm{~cm}$ at its longest dimensions and weighed $100 \mathrm{~g}$ (fig. 3). The histopathological examination was compatible with lipoma, with no lipoblasts, necrosis, or mitoses (fig. 4).

On late follow-up (180 days), the evolution was good with no recurrence of the tumor, as shown on the control echocardiography.

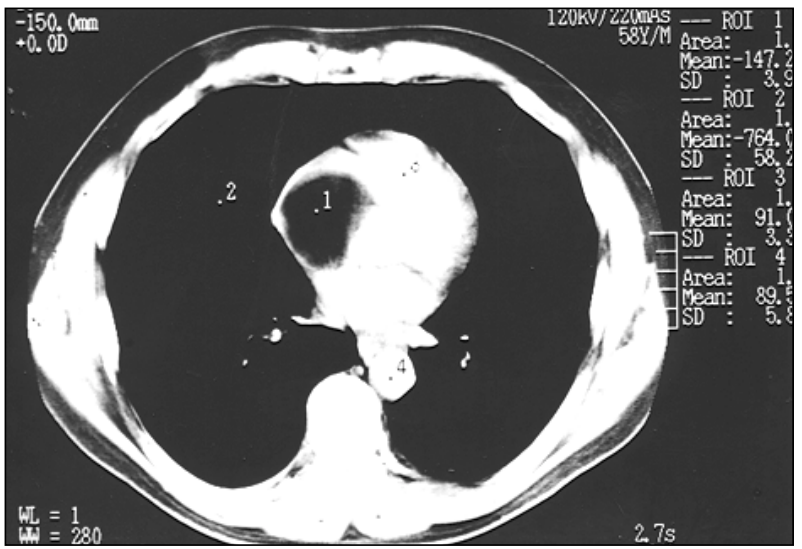

Fig. 2 - Tomographic image showing a low-density failure in the right atrial filling, measuring $7.0 \mathrm{~cm}$ in the anteroposterior axis and $5.0 \mathrm{~cm}$ in the transversal axis.

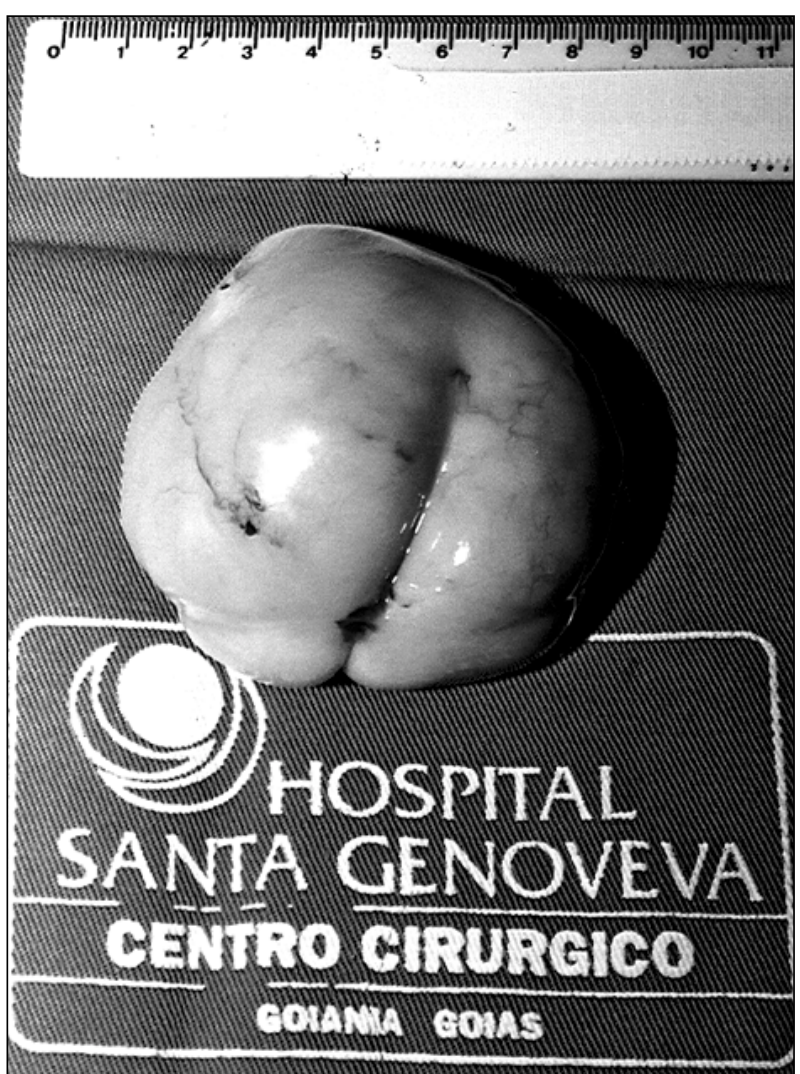

Fig. 3 -Gross anatomy of Lipoma.

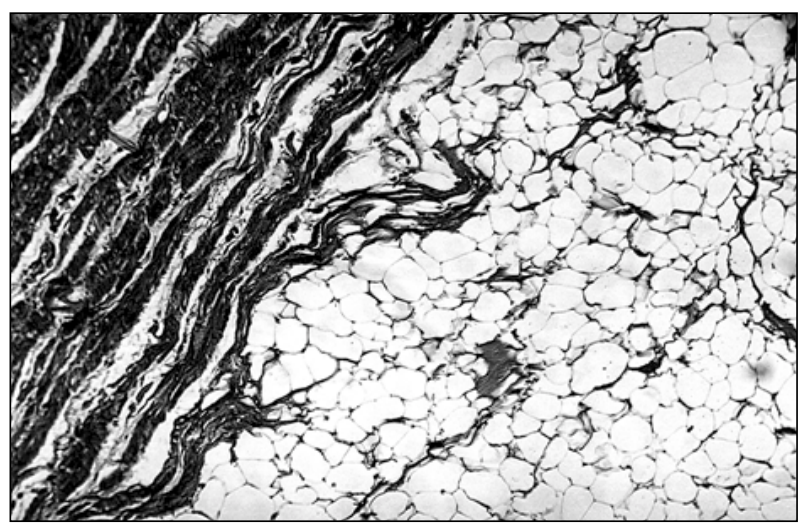

Fig. 4 - Gross appearance of the encapsulated yellowish homogeneous mass, which has a fatty appearance and elastic consistency.

\section{Discussion}

Lipoma is a tumor of adipose cells that originate in the epimyocardium. Its gross appearance is identical to that observed in lipomas in other areas; it may adhere either to the fibrous tissue (pericardium) or to the muscle tissue (subepicardium) and may also exhibit forms of lipomatous degeneration, such as fat necrosis and calcification ${ }^{2,10}$. Approximately $50 \%$ of these tumors have a subendocardial origin, $25 \%$ an intramyocardial origin (affecting most frequently the left ventricle, the right atrium, and the interatrial septum), and the remaining $25 \%$ a pericardial origin ${ }^{1,11}$. 
No report of malignancy or metastases exists ${ }^{2}$. Some authors have attempted to classify the neoplasia according to invasion of the surrounding tissues. Therefore, when adipose cells infiltrate the myocardium, the tumor is called a myolipoma; when connective tissue is present in the tumor, it is a fibrolipoma, and when the tumor is composed of pure fat with a free support reticulum, it is a lipoma.

Intracardiac tumors may manifest as disorders of atrioventricular or intraventricular conduction, as arrhythmias, or may interfere with myocardial contraction ${ }^{10,12}$, sudden death included ${ }^{12}$. Some cases, however, are diagnosed only during the postmortem examination, because only a few patients have clinical manifestations secondary to the tumor ${ }^{12}$, depending on its size and location. Galen et al. ${ }^{13}$ reported a case of left ventricular lipoma in a 52-year-old female patient, which manifested as angina on effort, despite the normal coronary anatomy. Morikami et al. ${ }^{14}$ reported a case of an asymptomatic 38-year-old patient who had an electrocardiographic alteration suggesting ventricular hypertrophy in a lipoma located in the inferior wall of the left ventricle. Zamir et al. ${ }^{15}$ reported the case of a 46 -year-old female with pulmonary embolism, a lipoma being the source of emboli. Lipomas of the cardiac valves are extremely rare. Behnam et al. ${ }^{16}$ reported 1 case of mitral regurgitation caused by multiple lipomas in the mitral valve in a 2 -year-old female.

In regard to etiology, some authors suspect a congenital origin in the group of the homeoplastic dysembryomas ${ }^{17}$. However, heterotopia of mesodermal embryonic cells may differentiate as lipocytes and cause lipomas in the mediastinum, pericardium, and interatrial septum ${ }^{18}$. From the histological point of view, lipomas are true neoplasias, constituted of mature adipose tissue, mainly large well-formed adipose cells of the adult type. The cardiac lipoma, like lipomas in other locations, may undergo fat necrosis and calcification.

Some tumors are diagnosed based on alterations revealed on physical examination, or through noninvasive methods ${ }^{12}$. Steiner ${ }^{19}$ reported that lipomas and fibromas might cause a difference in density between the cardiac and the tumoral images, because these tumors are more semitransparent than the surrounding tissues. The adipose tissue is semitransparent being between the clarity of the image of a gas and the opacity of that of the soft tissues and liquids ${ }^{18}$.

In the past few years, echocardiography has contributed to an increase in the number of cardiac tumors diagnosed, mainly in oligosymptomatic patients, showing its relation to cardiac structures and their dynamics. However, its sensitivity for differentiating tissue characteristics is limited.

In the present case, transesophageal echocardiography was highly accurate in locating the tumor in the atrial wall, which made the surgical strategy of atrial cannulation and incision much easier.

Computerized tomography has a great specificity for identifying the tumor, locating it in the heart, in addition to delineating its shape, dimension, and density. Lipomas usually have low density, which ranges from-80 to $115 \mathrm{Ho}-$ unsfield units ${ }^{20}$. The cells in lipomas may be characterized by the criterion proposed by Mendez et al. ${ }^{21}$, which considers the mean density of the adipose tissue, ie, density equal to or below -55 Hounsfield units.

Nuclear magnetic resonance is a noninvasive, highsensitivity, and high-specificity method; therefore, it may be useful, mainly in cases with extracardiac masses that compress cavities and simulate intracardiac mass. Nuclear magnetic resonance is also useful in cases of low-density mediastinal cysts, which computerized tomography may reveal as lipoma. The correct interpretation of nuclear magnetic resonance may require invasive studies or surgery.

In the present case, computerized tomography confirmed the intracardiac location of the tumor and defined it as a lipoma. Despite the voluminous mass, the patient was asymptomatic because of the low mobility of the tumor and the fact that it was adhered to the lateral wall of the right atrium, therefore, not interfering with the dynamics of the tricuspid valve.

\section{References}

1. McAllisterHA Jr. Tumors of the heart and pericardium. In: Silver MD, ed. Cardiovascular Pathollogy. $2^{\text {nd }}$ ed. New York: Churchill Livinstone Inc 1991; 2: 1297-333.

2. Heath D. Pathology of cardiac tumors. Am J Cardiol 1968; 21: 315-27.

3. Albanesi $\mathrm{F}^{\circ} \mathrm{FM}$, Castier MB, Sá VF, et al. Lipoma intrapericárdico. Arq Bras Cardiol 1991; 56: 309-12.

4. Matta R, Neelakandhan KS, Sandhyamani S. Right atrial lipoma. Case report. J Cardiovasc Surg 1996; 37: 165-8.

5. DollarAL, WallaceRB, KentKM,BurkhartMW,RobertsWC.Mitral valvereplacement for mitral lipoma associated with severe obesity. Am J Cardiol 1989; 64: 1405-7.

6. Ashar K, Hoeven KH. Fatal Lipoma of the heart. Am J Cardiovasc Pathol 1992; 4: 85-90.

7. Moulton AL, Jaretzki A, Bowman FO, Silverstein EF, Bregman D. Massive lipoma of heart. NY State J Med 1976; 76: 1820-5.

8. Harjola, Kulju A, Ketonen P. Epicardial lipoma. Scand J Thorac Cardiovasc Surg 1985; 19: 181
9. MaurerER. Successful removal of tumor of the heart. JThorac Surg 1952; 23:479-85.

10. Selzer A, Sakai FJ, Popper RW. Protean clinical manifestations of primary tumors of the heart. Am J Med 1972; 52:918.

11. Monsseaux E, Idy-Peretti I, Bittoun J, et al. MR tissue characterization of a right atrial mass: diagnosis of a lipoma. J Comput Assist Tomogr 1992; 16: 148-51.

12. Kloner RA. Cardiac tumors. In: Kloner RA, (ed). The Guide to Cardiology. New York: Jonh Wiley \& Sons, 1984: 439.

13. Galen PV Jr., Breyer R, Holliday R, et al. Tumors of the heart surgical considerations. J Cardiovasc Surg. 1984; $25: 5$.

14. Morikami Y,Higashi T, et al. Cardiac lipoma with changes of ST segment and T wave on electrocardiogram. Japanese Circulation J 1984; 58: 733-6.

15. Zamir D, Pelled B, Marin G, Weiner P. Cardiac lipoma of the septum with systemic and pulmonary emboli. Harefuah 1995; 129: 179-81, 223.

16. Behnam R, Williams G, Gerlis L, Walker D, Scott O. Lipoma of the mitral valve and papillary muscle. Am J Cardiol 1983; 51: 1459. 
17. Morere P, Stain JP, Hertzog P, Nouvet G, Denoix C. Les lipomes mediastinaux: à propos d'une observation. Ann Cir Thorac Cardiovasc 1972; 11: 417-22.

18. Medeiros $\mathrm{F}^{\circ} \mathrm{JH}$, Luiz C, Lopes EA, Jatene AD. Tumor radiolucente epi-pericardico: Lipoma. Apresentação de dois casos sob ponto de vista radiológico. Arq Bras Cardiol 1077; 30: 145-51.
19. Steiner RE. Radiologic aspects of cardiac tumors. Am J Cardiol 1968; 21:344-56

20. Moncada R, Baker M, Salinas M, et al. Diagnostic role of computed tomography in pericardial heart disease: congenital defects, thickening, neoplasm, and effucions. Am Heart J 1982; 103: 263-82.

21. Mendez Jr G, Isikoff Mb, Isikoff SK, Sinner WN. Fatty tumors of the thorax demonstrated by CT. Am J Roentgenol 1979; 133: 207-12. 